\title{
Adsorption of Cadmium (II) and Copper (II) onto Magnetic Organo-Bentonite Modified by 2-(3,4-Dihydroxyphenyl)-1, 3-Dithiolane from Aqueous Solutions
}

\author{
Naser Boroomand and Zahra Shokria
}

\begin{abstract}
In this study, the magnetic bentonite absorbent modified by 2-(3,4-dihydroxyphenyl)-1,3-dithiolane, was synthesized for simultaneous removal of two toxic heavy metals of cadmium and copper from soil and water samples. The influences of five dominant parameters of $\mathrm{pH}$, temperature, time and adsorbent amount on adsorption process were investigated. Via experiments, maximum adsorption percent of $98.5 \pm 0.5$ and 98.1 \pm 0.4 were obtained which showed the high adsorption potential of the proposed sorbent. The experimental data were found to be properly fitted to the Langmuir and Freundlich model which indicates that the sorption takes place on a heterogeneous material. The sorption capacities of 175.439 and 178.571(mg g-1) were achieved for cadmium and copper, respectively. Standard Error Estimates of 0.253 and 0.299 for $\mathrm{Cu}$ and $\mathrm{Cd}$, respectively, showed the fittest adsorption data after using this model. Also, Freundlich isotherm and Freundlich isotherm- linear plots were satisfactorily able to describe the adsorption of copper and cadmium by both adsorbents: N-bentonite and modified bentonite.
\end{abstract}

Index Terms-2-(3,4-dihydroxyphenyl)-1, 3-dithiolane, adsorption, magnetic organo-bentonite, heavy metal, flame atomic absorption spectrometry (FAAS).

\section{INTRODUCTION}

Heavy metals removal from various matrixes, especially soil, ground and underground waters, is a serious concern for scientists. Consequently, many separation techniques have been presented to extract heavy metals (e.g. $\mathrm{Cd}, \mathrm{Cu}, \mathrm{As}, \mathrm{Hg}$, $\mathrm{Pb}$, etc.) from various matrixes such as water and soil in order to avert environmental contamination. Among those, adsorption techniques have been attractively and widely used due to their simplicity and immediate accessibility. Therefore, a wide range of studies have been done to introduce new materials with high loading capacity to adsorb heavy metals and with indicative affinity, which leads to significant efficiency of heavy metals removal from the media [1]-[3]. Different materials such as silica gel [4] (Tran et al., 1999), aerobic granules [5], [6], zeolite [7] and clay [8], [9] have been reported to help remove heavy metals. In order to increase the heavy metals removal efficiency, modification of sorbent surface by surfactants [10]-[13] and thiols [14], [15] has been reported. Among all proposed sorbents, clay has

Manuscript received May 22, 2016; revised August 31, 2016.

Naser Boroumand is with the Department of Soil Science, Faculty of Agriculture, University of Jiroft, Jiroft, P. O. Box 8767161167, Iran (e-mail: nboroomand.uj@gmail.com).

Zahra Shokria is with University of Jiroft, Iran, Islamic (e-mail: Shokri@yahoo.com). been widely applied to avoid the release of heavy metals into the environment [16] Bentonite is a 2:1 type of clay which is very prevalent for adsorption of environmental contamination. In the present study, regarding the applications of surface functionalization of thiol group in adsorbent material for toxic soft metal ions, the synthesis of 2-(3, 4-dihydroxyphenyl)-1, 3-dithiolane (DHPDTO) (Scheme 1) and surface modification using DHPDTO coupling agents enhanced the adsorption capacity of bentonite. This new hybrid organic-inorganic material may be a good alternative for separation and pre-concentration of heavy metal ions. However, few research studies have focused on the interactions of heavy metals with the surface of bentonite modified by thiol group $(\mathrm{S}-\mathrm{H})$.

One of the main problems in the adsorption techniques is separation of the adsorbent from the medium. Magnetic sorbents such as zeolites [17]-[22] and bentonite [23] have been used for removal of heavy metals but so far magnetic bentonite has not widely been utilized in this case. In the present study, magnetic DHPDTO-Bentonite was synthesized and applied for the removal of two toxic metal ions of cadmium and copper. The influential parameters of $\mathrm{pH}$, the amount of sorbent, temperature and time were investigated.

\section{MATERIALS AND METHODS}

\section{A. Materials}

DHPDTO was synthesized and characterized by FT-IR, ${ }^{1} \mathrm{H}-\mathrm{NMR}$; their physical properties were compared with those reported in the literature. The standard stock solutions of cadmium (1000 $\left.\mathrm{mg} \mathrm{L}^{-1}\right)$ and copper (II) (1000 $\left.\mathrm{mg} \mathrm{L}^{-1}\right)$ were prepared by dissolving appropriate amounts of $\mathrm{Cd}$ $\left(\mathrm{NO}_{3}\right)_{2} .4 \mathrm{H}_{2} \mathrm{O}$ (Merck) and $\mathrm{Cu}\left(\mathrm{NO}_{3}\right)_{2}$ (Merck) in $1 \%$ nitric acid solution. Standard solutions of cadmium and copper were prepared daily by dilution of stock solutions. Deionized water was used for preparation for all solutions. Bentonite was purchased from Salafchegan with the following chemical composition (in wt. \%): $\mathrm{SiO}_{2}$ (65.04), $\mathrm{Fe}_{2} \mathrm{O}_{3}$ (1.67), $\mathrm{MgO}$ (1.87), $\mathrm{Al}_{2} \mathrm{O}_{3}$ (13.61), $\mathrm{CaO}$ (2.01), $\mathrm{TiO}_{2}$ (0.19), $\mathrm{Na}_{2} \mathrm{O}$ (2.26) and $\mathrm{K}_{2} \mathrm{O}(0.75)$.

\section{B. Instrumentation}

Cadmium and copper determination was carried out by a Buck Scientific's Atomic Absorption Spectrometer (Model 210 VGP, USA) with the hollow cathode lamps having wavelengths of $228.8 \mathrm{~nm}$ and $324.8 \mathrm{~nm}$ for cadmium and copper, respectively, using air-acetylene flame. The operating 
conditions were set as recommended by the manufacturer. The single line flow injection system consisting of peristaltic pump (Osmatic, MS-REGLO/8-100, Switzerland), and rotary injection valve (Redone, CA, USA) with a loop of $100 \mu \mathrm{L}$ capacity were used for effective control of the amount of sample and reproducibility of the measurements. The absorbance time response was monitored on an $\mathrm{x}$ - $\mathrm{t}$ chart recorder (L-250) and quantitative analysis was based on measurement of the peak height of transient signals. The $\mathrm{pH}$ measurements were carried out with a Met Rohm pH meter (model 691, Switzerland). Both Ultrasonic bath (Sonora Digital, DT255H, and Germany) and oven (Universal model UF 55, Germany) were used for magnetic zeolite preparation. IKA overhead stirrer (model RW 28 digital Package, Germany) with glass stirrer was utilized to stir the magnetic sorbent sample solution during adsorption process. A vibration-sample magnetometer (Magnates Dogfight Caver Co.) was used to characterize the magnetic properties of the synthesized magnetic bentonite. FT-IR spectra were run on a Broker, Equinox 55 spectrometer using the conventional ATR method.

\section{Preparation of 2-(3,4-dihydroxyphenyl)-1, 3-Dithiolane (DHPDTO)}

A mixture of 2,3-dihydroxy Benz aldehyde (10 moll), 1, 2-Ethanedithiol (12 moll) and 37\% BF3.SiO2 (0.3 g) was ground in a pestle at an ambient temperature. The progress of reaction was monitored by TLC. After the completion of the reaction, the products were dissolved in ethanol, filtered, and the solvent was evaporated. The obtained solid was recrystallized in chloroform (yield $=93 \%$ ).

The spectroscopic data of IR ${ }^{1} \mathrm{H}$ NMR and ${ }^{13} \mathrm{C}$ NMR are as bellow:

IR (Kerr) $\mathrm{Cm}^{-1}:$ 3411, 3263, 2955, 2909, 1606, 1519, 1467, 1385, 1342, 1296, 1262, 1108, 962, 881, 755, 717.

${ }^{1} \mathrm{H}\left(500 \mathrm{MHz}, \mathrm{CDCl}_{3} / \mathrm{DMSO}\right) 7.14(1 \mathrm{H}, \mathrm{d}, \mathrm{J}=2 \mathrm{~Hz}), 6.96$

$(1 \mathrm{H}$, did, $\mathrm{J}=8.15$ and $2 \mathrm{~Hz}), 6.82(1 \mathrm{H}, \mathrm{d}, \mathrm{J}=8.15 \mathrm{~Hz}), 5.61$

(1 H, s), 3.48-3.54 (2 H, m), 3.33-3.39 (2 H, m).

${ }^{13} \mathrm{C}\left(125 \mathrm{MHz}, \mathrm{CDCl}_{3} / \mathrm{DMSO}\right)$ 40.54, 56.64, 115.47, 115.50, 120.82, 132.76, 144.26, 144.40.

1) Preparation of magnetic bentonite and DHPDTO-Bentonite

The mixture of bentonite in $100 \mathrm{~mL}$ of ammonia solution (1 $\mathrm{M})$ was deoxygenated (solution $\mathrm{A}$ ). The solution of $\mathrm{FeCl}_{3} \cdot 6 \mathrm{H}_{2} \mathrm{O}(1 \mathrm{M})$ and $\mathrm{FeCl}_{2} \cdot 4 \mathrm{H}_{2} \mathrm{O}(2 \mathrm{M}$ in $\mathrm{HCl} 2 \mathrm{M})$ was deoxygenated too (solution $\mathrm{B}$ ). Then, the two solutions were mixed under nitrogen atmosphere by ultrasonic treatment. The solution was washed with oxygen-free deionized water for several times. Finally, the obtained magnetic bentonite was dried at $50{ }^{\circ} \mathrm{C}$ in the oven.

$\mathrm{N}$-Bentonite fractions with less than 100 mesh were treated by $1 \mathrm{moll} / \mathrm{L}$ sodium chloride solution to obtain homoeotic samples (Na-Bentonite). After complete exchange, the samples were washed with distilled water until they became free from chloride as tested by the $\mathrm{AgNO}_{3}$ solution as an indicator. Then, 50g Na-Bentonite was mixed with methanol containing the amount of DHPDTO equivalent to the CEC of bentonite in a beaker. After being mechanically stirred for 24 $\mathrm{h}$ at $25^{\circ} \mathrm{C}$, the mixture was filtered, and then washed several times with methanol. Dried at room temperature, it was activated for $1 \mathrm{~h}$ at $60^{\circ} \mathrm{C}$ to dehydrate, [24], [25], DHPDTO still remaining stable, and ground with a pestle to less than 100 mesh. This produced DHPDTO-Bentonite.

2) Adsorption process of $\mathrm{Cu}^{2+}$ and $\mathrm{Cd}^{2+}$

The $\mathrm{pH}$ of $10 \mathrm{~mL}$ sample solution containing $50 \mathrm{mg} \mathrm{L}^{-1}$ of $\mathrm{Cu}^{2+}$ and $\mathrm{Cd}^{2+}$ was adjusted at 6 by adding $0.1 \mathrm{moll} \mathrm{L}^{-1}$ nitric acid or sodium hydroxide. $50 \mathrm{mg} \mathrm{N}$-Bentonite or DHPDTO-Bentonite was added to the solution. The mixture was stirred for $10 \mathrm{~min}$ by an overhead stirrer. Then, the magnetic sorbent was separated from the solution by a magnet and the upper aqueous phase containing the residual cadmium and copper in the solution was used for determining the concentration by flow injection-flame atomic adsorption spectrometry.

\section{RESUlTS AND DISCUSSION}

\section{A. Effect of Initial $p H$}

Acidity or basicity of the aqueous medium plays an important role in the adsorption process. Therefore, the $\mathrm{pH}$ of the solution was investigated in the range of 2-10. The adsorption efficiency was at maximum in the $\mathrm{pH}$ range of 5-6. The decrease in adsorption of interested metal ions at low $\mathrm{pH}$ is owing to the competition of hydrogen ions with cadmium and cupper ions for occupation of the active sites on the surface of the sorbent. Also, the sorbent surface is protonated and cannot adsorb metal ions. And at high $\mathrm{pH}$ ranges, the adsorption efficiencies (adsorption of cadmium and cupper ions via the studied sorbent) decrease, likely due to the formation of metal hydroxides in the solution which reduces the adsorption of metal ions onto the surface of the sorbent. Therefore, a pH of 6 was selected for subsequent studies.

\section{B. The Effect of Amount of Sorbent}

The amount of synthesized magnetic organo-bentonite was studied in the range of $10-80 \mathrm{mg}$. According to the obtained results, as the amount of sorbent increases, the adsorption efficiency will consequently increase due to the enhancement of active and vacant sites for metal ions occupation and more contact surface between the metal ions which lead to more adsorption on the sorbent. From 10 to $50 \mathrm{mg}$ an increasing trend was observed and from 50 to $80 \mathrm{mg}$ the adsorption efficiencies were nearly constant for both ions. Therefore, the sorbent amount of $50 \mathrm{mg}$ was chosen for further studies.

\section{The Effect of Time}

Adsorption time is another factor which can noticeably influence the percent of metal ions removal due to acquiring the equilibrium between aqueous solution and adsorption process. Thus, the adsorption time was investigated from 3-20 min. According to the results, it can be concluded that the more the contact time is, the more complete the adsorption will be. The percent of metal ions removal from 3-10 min increased and after that no change was observed in the adsorption efficiency. Hence, the optimum time of 10 min was considered for simultaneous removal of cadmium and copper.

\section{The Effect of Temperature}

One of the most influential factors in all separation procedures especially adsorption processes is temperature. 
The effect of temperature was studied in the range of $25-55^{\circ} \mathrm{C}$. The results showed that along with increase in the temperature a very slight increase was observed in the process. It seems that at higher temperatures the mobility of ions in the solution increases and the ions adsorption on the sorbent is endothermic and by increasing the temperature the adsorption efficiency and the percent of metal ions removal will increase. Since the adsorption efficiency had no significant difference at higher temperatures, the ambient temperature of $25^{\circ} \mathrm{C}$ was selected for further studies.

TABLE I: ISOTHERM PARAMETERS FOR ADSORPTION OF CADMIUM AND COPPER ONTO THEMAGNETIC DHPDTO-BENTONITE AND N-BENTONITE UNDER OPTIMUM CONDITIONS

Langmuir isotherm-linear $\quad$ Frewndlich isotherm-linear

\begin{tabular}{|c|c|c|c|c|c|c|c|c|c|c|c|}
\hline Ion & adsorbent & $\underset{\left(m g g^{-J}\right)}{Q_{\text {ors }}}$ & $\begin{array}{c}b \\
\left(L m g^{-2}\right)\end{array}$ & $R^{2}$ & $S E E$ & $R_{L}$ & $K_{2}$ & $I / n$ & $n$ & $S E E$ & $R^{2}$ \\
\hline \multirow[t]{2}{*}{$\mathrm{Cu}$} & $N$-Bentonite & 70.422 & 0.011 & 0.9880 & 0.4344 & 0.119 & 2.073 & 0.587 & 1.702 & 0.1094 & $\begin{array}{c}0.941 \\
2\end{array}$ \\
\hline & $\begin{array}{c}\text { Magnetic } \\
\text { DHPDTO- } \\
\text { Bentonite }\end{array}$ & 178.571 & 0.052 & 0.9722 & 0.0716 & 0.116 & 15.212 & 0.385 & 1.961 & 0.1282 & $\begin{array}{c}0.945 \\
7\end{array}$ \\
\hline \multirow[t]{2}{*}{$C d$} & $N$-Bentonite & 70.922 & 0.009 & 0.9857 & 0.5198 & 0.0175 & 3.257 & 0.485 & 2.063 & 0.1139 & $\begin{array}{c}0.907 \\
2\end{array}$ \\
\hline & $\begin{array}{c}\text { Magnetic } \\
\text { DHPDTO- } \\
\text { Bentonite }\end{array}$ & 175.439 & 0.056 & 0.9728 & 0.0792 & 0.0188 & 19.328 & 0.436 & 2.294 & 0.1021 & $\begin{array}{c}0.964 \\
3\end{array}$ \\
\hline
\end{tabular}

\section{E. Adsorption Isotherm Study}

The adsorption isotherms indicate the partition of adsorbate molecules between the liquid sample solution and solid sorbent in the adsorption process. In other words, the adsorption isotherms clarify the relationship between the adsorbent and adsorbate at a specific temperature. Therefore, to evaluate the adsorption isotherm of the proposed method, the common isotherms of Langmuir and Freundlich were studied at different concentrations in the range of $5-50 \mathrm{mg} \mathrm{L}^{-1}$ at optimum temperature conditions. Langmuir isotherm has a rational basis and implies the monolayer adsorption on a homogenous adsorbent. As a site is occupied by an iron, no further molecule can be adsorbed at that site [26]. The Langmuir equation is as below [20]:

$$
C_{\mathrm{e}} / Q_{e}=1 /\left(Q_{m} b\right)+C_{e} / Q_{m}
$$

where $Q_{m}$ is the saturation adsorption capacity $\left(\mathrm{mg} \mathrm{g}^{-1}\right)$ and b is the constant related to the free energy of adsorption which were obtained from the slope and the intercept of equation. The favorability of $\mathrm{Cd}^{2+}$ and $\mathrm{Cu}^{2+}$ adsorption for the DHPDTO-Bentonite can be assessed by the dimensionless constant called separation factor, $R_{L}$.

$$
R_{L}=1 /\left(1+b C_{0}\right)
$$

In this equation, $C_{0}\left(\mathrm{mg} \mathrm{g}^{-1}\right)$ is the highest initial ions concentration in adsorption isotherm studies. The value of RL implies the unfavorable $\left(R_{L}>1\right)$, linear $\left(R_{L}=1\right)$, favorable $\left(0<R_{L}<1\right)$, and irreversible $\left(R_{L}=0\right)$ type of the adsorption isotherm. As the results show in Table 1 , the values of $R_{L}$ for two ions are $0<R_{L}<1$ which are favorable for adsorption isotherm [27], [28].

The Freundlich isotherm is an empirical equation which is commonly applied for many adsorption processes. The Freundlich isotherm was also considered for the process. The equation is as below:

$$
Q_{e}=K_{f} C_{e}{ }^{(1 / n)}
$$

This can be linearized as following:

$$
\log Q_{e}=\log K_{f}+1 / n \log C_{e}
$$

where the $K_{f}$ is the Freundlich constant related to the adsorbent capacity, and $\mathrm{n}$ is the constant indicative of the intensity of the adsorption process. The values of the constant $\mathrm{n}$ and $K_{f}$ were calculated from the slope and the intercepts of equation (see Table I). The Freundlich intensity constants of $\mathrm{Cd}^{2+}$ and $\mathrm{Cu}^{2+}$ were as $\mathrm{n}>1$ which show the significant adsorption of $\mathrm{Cd}^{2+}$ and $\mathrm{Cu}^{2+}$ in the proposed procedure even at high ions concentration.

The adsorption isotherms were also considered for $\mathrm{N}$-bentonite. As the results show, for both $\mathrm{Cu}$ and $\mathrm{Cd}, \mathrm{K}$ values were observed to be higher for DHPDTO- Bentonite than for N-Bentonite; the results are tabulated in Table I. In $\mathrm{N}$-Bentonite adsorbent, with increased $\mathrm{C}_{\mathrm{e}}$, first, there was a rise in the amount of adsorption with increased slope and then it reached an almost stable state. In DHPDTO-Bentonite adsorbent, with increased $\mathrm{C}_{\mathrm{e}}$, no specific rise in the slope was observed. The diagrams showed that the models that fitted the data (on the adsorption of copper and cadmium) were highly correlated in the studied treatments.As shown in Table I, Langmuir isotherm is plotted by mean correlation coefficients of 0.9801 and 0.9792 for $\mathrm{Cu}$ and $\mathrm{Cd}$, respectively. The Standard Error Estimates of 0.253 and 0.299 obtained for $\mathrm{Cu}$ and $\mathrm{Cd}$ ( respectively) showed that the adsorption data were most and best fitted to this model. Langmuir and Freundlich isotherms were well corresponded with data on the absorption. Maximum absorption capacities obtained from the absorption isotherms were 175.43 and 178.57 for cadmium and copper, respectively. Also, Freundlich isotherm and Freundlich isotherm- linear plots were satisfactorily able to describe the adsorption of copper and cadmium by both adsorbents: Nbentonite and modified bentonite. 


\section{F. Desorption of Magnetic Organo-Bentonite}

The reusability of the sorbent is one of the most considerable parameters which indicates the potential of the adsorption process. Therefore, the used sorbent was desorbed in $0.1 \mathrm{M}$ solution of $\mathrm{HCl}$. The sorbent was put in contact with the acid solution for $30 \mathrm{~min}$ at room temperature. This process was repeated three times. Each time, the concentration of cadmium and copper was determined by atomic absorption spectrometry to ensure that there were no residual metal ions in the sorbent. Then, the sorbent was rinsed by deionized water several times to remove any remaining contamination in the sorbent.

\section{G. Regeneration}

The regenerated sorbent was reused from 1 to 6 times in adsorption processes. The obtained results in Fig. 1 showed that the adsorption efficiency was constant up to three times after which a decreasing trend was observed.

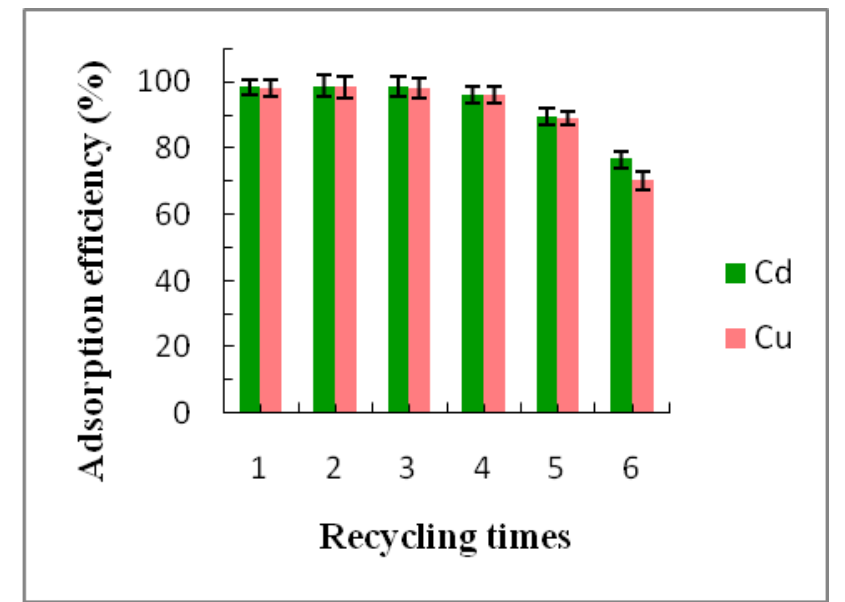

Fig. 1. The effect of recycling times on adsorption efficiency of the sorbent at optimum conditions.

\section{CONCLUSIONS}

The easily-separable Magnetic DHPDTO-Bentonite was synthesized and applied for simultaneous removal of cadmium and copper from aqueous solutions. The optimum conditions of $6,25{ }^{\circ} \mathrm{C}, 30 \mathrm{~min}$, and $50 \mathrm{mg}$, for $\mathrm{pH}$, temperature, time and adsorbent amount were acquired, respectively. The experimentally achieved max adsorption percent of $98.5 \pm 0.5$ and $98.1 \pm 0.4$ were obtained which showed the high adsorption potential of the proposed sorbent. The cadmium and copper removal percent of $98.9 \pm 0.5$ and $98.3 \pm 0.4$ were achieved under optimum conditions. The results showed that the applied sorbent could properly adsorb two metal ions simultaneously in the media with a noticeable efficiency. The VSM revealed the magnetic properties of the synthesized magnetic bentonite. The studies on adsorption isotherms showed favorability and fitting of the process for/to Langmuir and Freundlich isotherms. Moreover, the proposed sorbent-magnetic DHPDTO-Bentonite- utilized in this study can be properly applied in industrial scale due to its low cost, easy separation and high percentage of ion removal.

\section{ACKNOWLEDGEMENTS}

University of Jiroft is acknowledged for financially supporting this work.

\section{REFERENCES}

[1] S. H. Lin, S. L. Lai, and H. G. Leu, "Removal of heavy metals from aqueous solution by chelating resin in a multistage adsorption process," J. Hazard. Mater, vol. 76, pp. 139-153, 2000.

[2] I. L. Lagadic et al., "Highly Effective Adsorption of Heavy Metal Ions by a thiol-functionalized magnesium phyllosilicate clay," Environ. Sci. Technol., vol. 35, pp. 984-990, 2001.

[3] A. Demirbas, "Adsorption of lead and cadmium ions in aqueous solutions onto modified lignin from alkali glycerol delignication," J. Hazard. Mater, vol. 109, pp. 221-226, 2004.

[4] J. Vereš and Z. Orolínová, "Study of the treated and magnetically modified bentonite as possible sorbents of heavy metals," Acta Montanistica Slovaca, vol. 14, pp. 152-155, 2009.

[5] J. H. Tay et al., "The effects of shear force on the formation, structure and metabolism of aerobic granules," Appl. Microbiol. Biotechnol., vol. 57, pp. 227-233, 2001.

[6] Y. Liu et al., "A general model for biosorption of $\mathrm{Cd}^{2+}, \mathrm{Cu}^{2+}$ and $\mathrm{Zn}^{2+}$ by aerobic granules," J. Biotechnol., vol. 102, pp. 233-239, 2003.

[7] C.-F. Lin et al., "Stabilization of cadmium contaminated soils using synthesized zeolite," J. Hazard. Mater, vol. 60, pp. 217-226, 1998.

[8] F. Barbier et al., "Adsorption of lead and cadmium ions from aqueous solution to the montmorillonite/water interface," Colloids and Surfaces A: Physicochemical and Engineering Aspects, vol. 166, pp. 153-159, 2000.

[9] D. Dermatas and X. Meng, "Utilization of fly ash for stabilization/solidification of heavy metal contaminated soils," Engineering Geology, vol. 70, pp. 377-394, 2003.

[10] M. Shin et al., "Effect of surfactant alkyl chain length on soil cadmium desorption using surfactant/ligand systems," Chemosphere, vol. 58, pp. 735-742, 2005.

[11] X. Jing et al., "Biosorption of $\mathrm{Cr}(\mathrm{VI})$ from simulated wastewater using a cationic surfactant modified spent mushroom," Desalination, vol. 269, pp. 120-127, 2011.

[12] J. Lin et al., "Adsorption characteristics of copper (II) ions from aqueous solution onto humic acid-immobilized surfactant-modified zeolite," Colloids and Surfaces A: Physicochemical and Engineering Aspects, vol. 384, pp. 9-16, 2011.

[13] K. S. Soliman et al., "Synthesis and characterization of ZSM-5 zeolite from rice husk ash and their adsorption of $\mathrm{Pb} 2+$ onto unmodified and surfactant-modified zeolite," Separation and Purification Technology, vol. 83, pp. 38-44, 2011.

[14] L. Mercier et al., "Preparation, characterization, and applications as heavy metals sorbents of covalently grafted thiol functionalities on the interlamellar surface of montmorillonite," Environ. Sci. Technol., vol. 29, pp. 1318-1323, 1995.

[15] I. S. Alferiev and I. Fishbein, "Activated polyurethane modified with latent thiol groups," Biomaterials, vol. 23, pp. 4753-4758, 2002.

[16] S. E. Bailey et al., "A review of potentially low-cost sorbents for heavy metals," Water Research, vol. 33, pp. 2469-2479, 1999.

[17] A. B. Bourlinos et al., "A simple route towards magnetically modified zeolites," Microporous Mesoporous Mater, vol. 58, pp. 155-162, 2003.

[18] I. W. Nah et al., "Removal of $\mathrm{Pb}$ ion from water by magnetically modified zeolite," Miner. Eng., vol. 19, pp. 1452-1455, 2006.

[19] I. W. Nah et al., "A simple synthesis of magnetically modified zeolite," Powder Technol., vol. 177, pp. 99-101, 2007.

[20] H. Faghihian et al., "Synthesis of a novel magnetic zeolite nanocomposite for removal of $\mathrm{Cs}+$ and $\mathrm{Sr} 2+$ from aqueous solution: Kinetic, equilibrium, and thermodynamic studies," J. Colloid Interface Sci., vol. 393, pp. 445-451, 2013.

[21] H. Liu et al., "Magnetic zeolite NaA: Synthesis, characterization based on metakaolin and its application for the removal of $\mathrm{Cu} 2+, \mathrm{Pb} 2+$, Chemosphere, vol. 91, pp. 1539-1546, 2013.

[22] H. Faghihian et al., "Evaluation of a new magnetic zeolite composite for removal of $\mathrm{Cs}+$ and $\mathrm{Sr} 2+$ from aqueous solutions: Kinetic, equilibrium and thermodynamic studies," Comptes Rendus Chimie, vol. 17 , pp. 108-117, 2014

[23] D. Wu et al., "Preparation, characterization and adsorptive study of rare earth ions using magnetic GMZ bentonite," Applied Clay Science, pp. 62-63, 87-93, 2012.

[24] P. Aranda et al., "Intercalation of macrocyclic compounds (crown ethers and cryptands) into 2:1 Phyllosilicates. stability and calorimetric study," Langmuir, vol. 10, pp. 1207-1212, 1994. 
[25] Y. Liu et al., "Adsorption of copper and lead in aqueous solution onto bentonite modified by 4'-methylbenzo-15-crown-5," Journal of Hazardous Materials, vol. 137, pp. 1149-1155, 2006.

[26] S. Sohrabnezhad and A. Pourahmad, "Comparison absorption of new methylene blue dye in zeolite and nanocrystal zeolite," Desalination, vol. 256, pp. 84-89, 2010.

[27] D. Mohan and S. Chander, "Single, binary, and multicomponent sorption of iron and manganese on lignite," J. Colloid Interface Sci. vol. 299 , pp. 76-87, 2006.

[28] M. Shirani et al., "Optimization of simultaneous removal of methylene blue, crystal violet, and fuchsine from aqueous solutions by magnetic NaY zeolite composite," Water, Air, Soil Pollut., vol. 225, pp. 1-15, 2014.

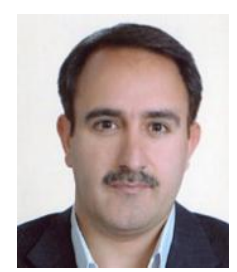

Nasser Boroomand is an assistant professor at Shahid Bahonar Universiy of Kerman and University of Jiroft where he teaches masters' courses in the Soil Science Department. 